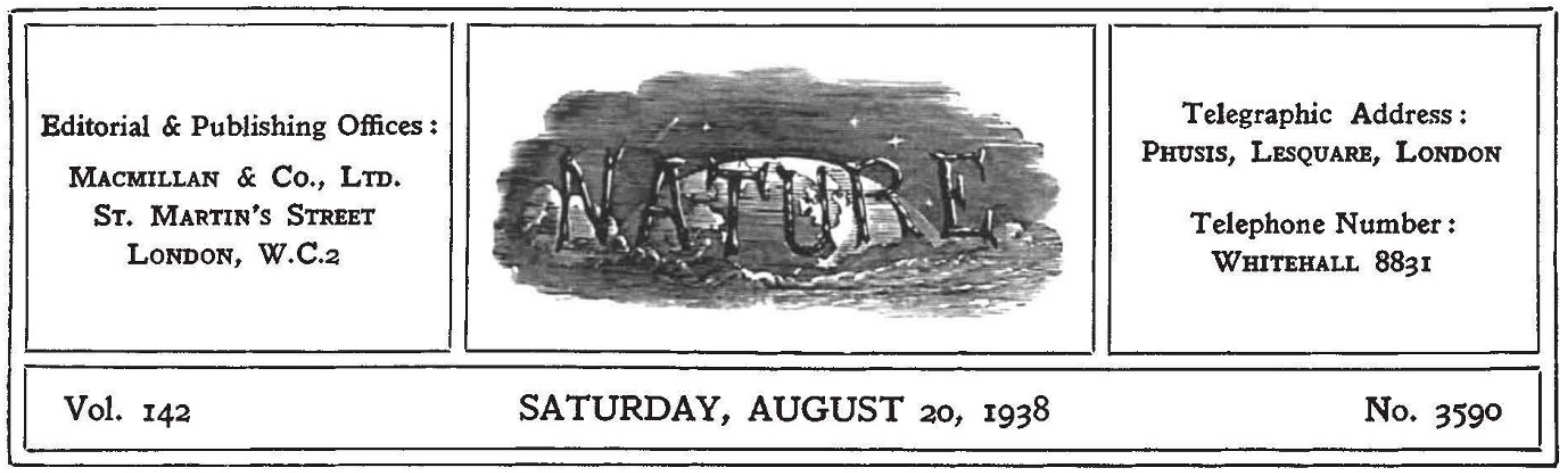

\title{
The Significance of Vision for Scientific Progress
}

$\mathrm{L}$ ORD RAYLEIGH'S presidential address to the British Association, which is printed in full in a Supplement to this issue of NATURE, is divided into two distinct parts under two titles. The first part, dealing with "Vision in Nature and Vision aided by Science", is a masterly general survey of developments in this field, which have taken place largely within the last two or three decades. In simple and direct language-itself a model of what such a survey should be-Lord Rayleigh describes the fundamental aspects of human vision and passes on to review the various ways in which the mechanism of the eye, employed as a means of observation, has been supplemented. The use of lenses, the telescope, the microscope, cathode rays, X-rays, spectroscopy and colour vision, photography and the sensitization of photographic plates, the photo-electric detection of radiation and television are all touched on, the salient features skilfully emphasized and the limitations and prospects of development duly noted. This part of Lord Rayleigh's address will surely bring home the vital fact that the largest part of our knowledge of Nature has been obtained by the sense of sight, and will remind us that progress by this means is not yet exhausted but bids fair, indeed, to go forward to fresh discoveries.

Very important parts of knowledge come, we remember, by the interpretation of images obtained by various optical devices with or without intermediate detection or recording. They are generally found as two-dimensional records of some object-field, although by kinematography and allied methods, and by stereoscopy, the senses of movement and three-dimensional extension can be obtained. But it is probably true that the newer technical methods, for example, the ultraviolet microscope, the iconoscope, and the like have not been exploited to a tithe of their possibilities by those who might use them to the greater advantage. The tendency of biological workers to use the microscope more as an automatic machine, and less as a research instrument, has been regretfully commented upon by those in a position to know the modern way. It is true that these methods are available, but they demand a certain training for use-a price which few are apparently willing to pay.

This is true in the extreme sense of the electron microscope, the invention which seems to open up a new world to more 'direct' observation. We are, as Lord Rayleigh remarks, very far from the perfecting of such instruments ; those who expect them to be sold at a cheap rate in instrumentmakers' shops, and to be operated by the laboratory boy, will be disappointed. It will be necessary to recapture the spirit of the early microscopists, for whom the labour of grinding their lenses was not too tedious to be faced, although the difficulties now encountered with high-vacuum technique and the design of electron-optical lenses are quite of another character and not less formidable even to the most sophisticated. The results obtained, especially in the microscopy of colloids, are extremely promising, and it seems almost certain that in some fields the method will far surpass anything possible to the optical microscope.

"Seeing is believing", no doubt, but it is interesting to speculate how far 'seeing' can go, when the worlds to which we would penetrate are so far out of reach of feeling and the other senses which help to make up our world of experience. 